\title{
A standardised framework for analysing animal detections from automated tracking arrays
}

\author{
Vinay Udyawer ${ }^{1,2^{*}}$ (D), Ross G. Dwyer ${ }^{3}$, Xavier Hoenner ${ }^{4}$, Russell C. Babcock ${ }^{5}$, Stephanie Brodie ${ }^{6,7}$, \\ Hamish A. Campbell ${ }^{8}$, Robert G. Harcourt ${ }^{9,10}$, Charlie Huveneers ${ }^{11}$, Fabrice R. A. Jaine ${ }^{9,10}$, \\ Colin A. Simpfendorfer ${ }^{2}$, Matthew D. Taylor ${ }^{6,12}$ and Michelle R. Heupel 2,13
}

\begin{abstract}
Background: Over the past 15 years, the integration of localised passive telemetry networks into centralised data repositories has greatly enhanced our ability to monitor the presence and movements of highly mobile and migratory species. These large-scale networks are now generating big data, allowing meta-analyses across multiple species, locations, and temporal scales. Broad-scale comparisons of animal movement metrics are constrained by the use of diverse analytical techniques among researchers. Accordingly, there is a need for a tool-set to assist in calculating animal movement metrics that can be easily applied to datasets from local studies to large-scale cooperative networks.

Results: We present a standardised framework and an associated analysis tool-set that facilitates the calculation of a range of activity space and movement metrics for passive telemetry datasets. Application of the tool-set is demonstrated using data from the Integrated Marine Observing System continental-scale network of underwater acoustic receivers. We show how the metrics can: (1) be directly compared among multiple species monitored at multiple sites; (2) be compared among multiple species tagged at a single study site; and (3) assess changes in activity space metrics over time.

Conclusions: Establishing a framework and tool-set to analyse data from large-scale networks progresses the field of passive telemetry beyond the traditional individual-, species-, or location-centric approaches to facilitate national- or international-scale outputs that better address important questions in the field of movement ecology.
\end{abstract}

Keywords: IMOS, Passive telemetry, Acoustic telemetry, Spatial ecology, Fish tracking, Big data, Species comparisons, VTrack, adehabitat, sp

\section{Background}

Advances in animal tracking technologies have vastly improved our capacity to monitor animal movements over large temporal and spatial extents [e.g. 1, 2]. One of the most widely used approaches is to deploy passive tracking arrays, where animal-borne radio or acoustic transmitters are detected by an array of static receiver stations [3]. This technology enables the tracking of a large

\footnotetext{
*Correspondence: v.udyawer@aims.gov.au

${ }^{1}$ Arafura Timor Research Facility, Australian Institute of Marine Science, Darwin, NT 0810, Australia

Full list of author information is available at the end of the article
}

number of individuals for longer periods of time than can be achieved using larger, more expensive satellite or GPS devices. Passive tracking approaches have been used extensively in terrestrial [4] and aquatic systems [5] and have led to globally important findings in conservation biology and fisheries science [e.g. 6]. Increasing use of these technologies combined with recognition of their cost-effectiveness has seen the development of local and international collaborative research networks [e.g. 4, 7].

Collaborative, passive telemetry networks have been established around the world to share data between receiver arrays and projects. Aquatic networks include the Ocean Tracking Network [Canada; 7], Florida 
Atlantic Coast Telemetry [USA; 8], Acoustic Tracking Array Platform [South Africa; 9], and others summarised in Hussey et al. [5], while terrestrial networks include LifeWatch [Belgium; 10] and Motus Wildlife Tracking System [North America; 4]. In Australia, a collaborative acoustic tracking network is supported with national infrastructure through the Integrated Marine Observing System (IMOS) [11]. The objective of the IMOS Animal Tracking Facility (IMOS ATF) is to facilitate national-scale movement studies through the provision of a national backbone of tracking infrastructure and a national data repository of detections and associated deployment records (https://animaltracking. aodn.org.au/) [12]. The establishment of large-scale collaborative networks has created the opportunity for researchers to share data within the animal telemetry community $[13,14]$. This has increased the geographic scope at which ecological data can be collected, facilitating investigations of broad-scale ecological processes across species, locations, and time [15].

Despite implementation of network infrastructure and data sharing arrangements, analysis of animal tracking data is most commonly conducted with a species-, habitat-, or site-centric focus [6]. The ability to explore broad ecological questions relies, in part, to accessing a suitable tool-set that can facilitate analyses of these large data sets. One of the benefits of such a tool-set is the capacity to produce standardised metrics to allow direct comparison across study sites and species. However, no such tool-sets are available for analysing passive telemetry data. While there are some commonly used analysis methods (e.g. home range analysis, Residency Index), variation in analytical approaches between studies typically precludes comparative analyses [e.g. 16-18]. For example, activity space estimates (95\% contour areas from fixed kernel utilisation distributions; KUD) calculated from passive acoustic monitoring have been published for five species at a single location, Mangrove Bay on Ningaloo Reef, Western Australia, including herbivores [Kyphosus bigibbus $1.6 \mathrm{~km}^{2}$; 19], mesopredators [Lethrinus nebulosus $8.5 \mathrm{~km}^{2}$; 20] and sharks [Carcharhinus melanopterus $12.8 \mathrm{~km}^{2}$; Carcharhinus amblyrhynchos $19.6 \mathrm{~km}^{2} ; 21$, Carcharhinus cautus $\left.3.6 \mathrm{~km}^{2} ; 22\right]$. In each case, different analytical approaches that account for spatiotemporal autocorrelation (e.g. estimation of short-term centres of activity, randomisation within receiver range) in subtly different ways and a variety of smoothing factors were used, making direct comparisons unreliable because KUD estimations are sensitive to the chosen smoothing factor [23]. Application of a single tool-set with defined parameters could produce directly comparable results for each of these species.
Our proposed universal framework and associated tool-set include a number of analysis techniques that are frequently used in passive telemetry studies [24]. Passive telemetry studies use detection patterns of a tagged animal within a fixed array to understand movement patterns, habitat use, and activity space. Raw detection data are typically used to calculate metrics of detection (e.g. number of detections; number of days detected; number of receivers detected on), dispersal (e.g. distances and bearings between consecutive detections; distances and bearings between each detection and release site), and activity space (e.g. home range areas). Here, we provide a universal framework and workflow to standardise the calculation of these commonly used animal movement metrics and demonstrate how this approach can be applied across large-scale telemetry networks.

The VTrack package, developed and used in the R statistical environment [25], provides a suite of analysis tools to calculate animal movement metrics using passive acoustic telemetry data [26]. VTrack was initially developed for linear systems (e.g. rivers) and did not provide standardised metrics of activity space of tagged animals. The original package was also not built to integrate data held within large-scale telemetry data repositories with multiple data contributors. We have extended the VTrack package to include the Animal Tracking Toolbox (ATT), a tool-set that includes a collection of new functions to estimate metrics of detection, dispersal, short-term centres of activity and home range from passive telemetry datasets. The methods used to calculate home range areas using node-based datasets are constantly evolving, with a multitude of techniques being used and developed to provide more accurate estimates of activity space. The ATT provides a repeatable technique to calculate estimates of activity space using three commonly used methods: the minimum convex polygon (MCP), fixed kernel utilisation distribution (KUD), and kernel utilisation distributions estimated using Brownian Bridge movement models (often referred to as UD, henceforth referred to as BB-KUD here).

The new toolbox includes the capacity to synthesise data from cooperative animal tracking networks. These new functions are designed to be used in conjunction with existing $\mathrm{R}$ packages like adehabitat $H R$ [27] and $s p$ [28] that have themselves become standard tools used to assess animal movement and spatial data. Using three case studies of acoustically tracked fishes in Australia, we describe this new functionality and how it can synthesise data collected from multiple projects within a large-scale tracking network and archived within the IMOS ATF. Our tool-set and workflow therein can be applied to other large-scale acoustic telemetry data infrastructure or other animal 
movement datasets collected by an array of passive receivers (e.g. fixed radio towers or passive integrated transponder tag antennas).

\section{Results}

The ATT is a collection of functions within the VTrack package (Table 1) implemented in the $\mathrm{R}$ statistical environment [25] (Fig. 1, Table 1). These functions can be run in series to implement our proposed framework and to transform individual detection data files with metadata into a range of standardised detection metrics, dispersal metrics, and activity space metrics (Fig. 1, see Appendix for proposed $\mathrm{R}$ workflow using ATT functions). Node-based telemetry networks typically comprise large numbers of static signal receivers installed over broad geographic areas. These networks record positional and sensor data from signal transmitters deployed on multiple animals by many research groups and institutions. The sheer scale of these networks means a strict quality control (QC) process is an essential first step to ensure data utilised in subsequent analyses are complete and accurate. In the present study, acoustic detection data from the IMOS ATF acoustic telemetry network underwent a flexible $\mathrm{QC}$ procedure that validate individual raw detections based on a series of tests to identify and discard false detections within the network [12]. We emphasise the importance of QC procedures prior to analysis of passive telemetry data for studies using data from a single site or installation, to large-scale cooperative networks consisting of multiple users and multiregional installations.

\section{Case Study 1: Activity space and dispersal metrics of multiple species across multiple study sites}

Dispersal metrics and activity space were compared among four species (Yellowfin Bream, Acanthopagrus australis $n=28$ tags; Yellowtail Kingfish, Seriola lalandi $n=24$ tags; Grey Reef Shark, Carcharhinus amblyrhynchos $n=27$ tags; and Bull Shark, Carcharhinus leucas $n=28$ tags) and across multiple sites around Australia (Fig. 2). To enable cross-site comparisons, all models were weighted by the estimated size of the array (i.e. area encompassing listening ranges of regional installations). Within each species, individuals displayed similar mean step dispersal distances among study sites (ANOVA; $p>0.05$ for all species comparisons, Fig. 2). Animals monitored in southern sites displayed larger or equivalent maximum step dispersal distances than at northern sites even with installation array size considered in models (Fig. 2, Table 2). Mean estimated activity spaces (area within 95\% contour of Brownian bridge kernel utilisation distributions; 95\% BB-KUD) were significantly larger in Yellowtail Kingfish and Bull Sharks in southern sites (ANOVA; $p<0.05$, Fig. 2), but inter-site differences in mean activity space were not significant in Yellowfin Bream and Grey Reef Sharks (Fig. 2, Table 2). Among species groups, measurements of dispersal between consecutive detections and overall 95\% BB-KUD showed that Bull Sharks displayed the largest mean maximum step dispersal distances $(511.6 \pm 182.3 \mathrm{~km})$ and maintained large activity spaces $\left(10,066.3 \pm 6732.9 \mathrm{~km}^{2}\right)$ followed by Yellowtail Kingfish $\left(115.7 \pm 31.2 \mathrm{~km}^{2}\right)$ (Fig. 2; Table 2). Grey Reef Sharks and Yellowfin Bream displayed small mean maximum step dispersal distances $(13.5 \pm 4.5 \mathrm{~km}$ and $72.2 \pm 19.1 \mathrm{~km}$, respectively) and maintained

Table 1 Summary of the Animal Tracking Toolbox (ATT)

\begin{tabular}{|c|c|}
\hline Function & Summary \\
\hline setupData() & $\begin{array}{l}\text { Sets up input data for smooth functioning of subsequent ATT functions. Produces an 'ATT' classed object consisting a list } \\
\text { of detection data, receiver locations and tag information }\end{array}$ \\
\hline detectionsummary () & $\begin{array}{l}\text { Requires input object of class 'ATT'. Produces a list containing standard detection metrics for: } \\
\text { (1) full tag period and } \\
\text { (2) user defined temporal subsets (i.e. monthly, weekly detection metrics) }\end{array}$ \\
\hline dispersalsummary() & $\begin{array}{l}\text { Requires input object of class 'ATT'. Produces a list containing dispersal distances and bearings between: } \\
\text { (1) consecutive detections and } \\
\text { (2) between each detection and tag release site }\end{array}$ \\
\hline $\operatorname{COA}()$ & $\begin{array}{l}\text { Requires input object of class 'ATT'. Produces a 'COA' classed object consisting of a data table with short-term centres of } \\
\text { activity within user defined time steps }\end{array}$ \\
\hline HRSummary ( ) & $\begin{array}{l}\text { Requires input object of class 'COA'. Produces a list containing standardised activity space metrics (i.e. Minimum convex } \\
\text { polygon area, } 50 \% \text { and } 95 \% \text { KUD and BB-KUD contour areas) for: } \\
\text { (1) full period of tag life, and } \\
\text { (2) user-defined subsets (i.e. monthly, weekly activity spaces) }\end{array}$ \\
\hline
\end{tabular}

The ATT is a collection of functions in the VTrack package that enables quick, standardised estimates of detection, dispersal and activity space metrics from telemetry data obtained using an array of fixed receiver stations and enables standardised analysis from large-scale cooperative passive telemetry networks 


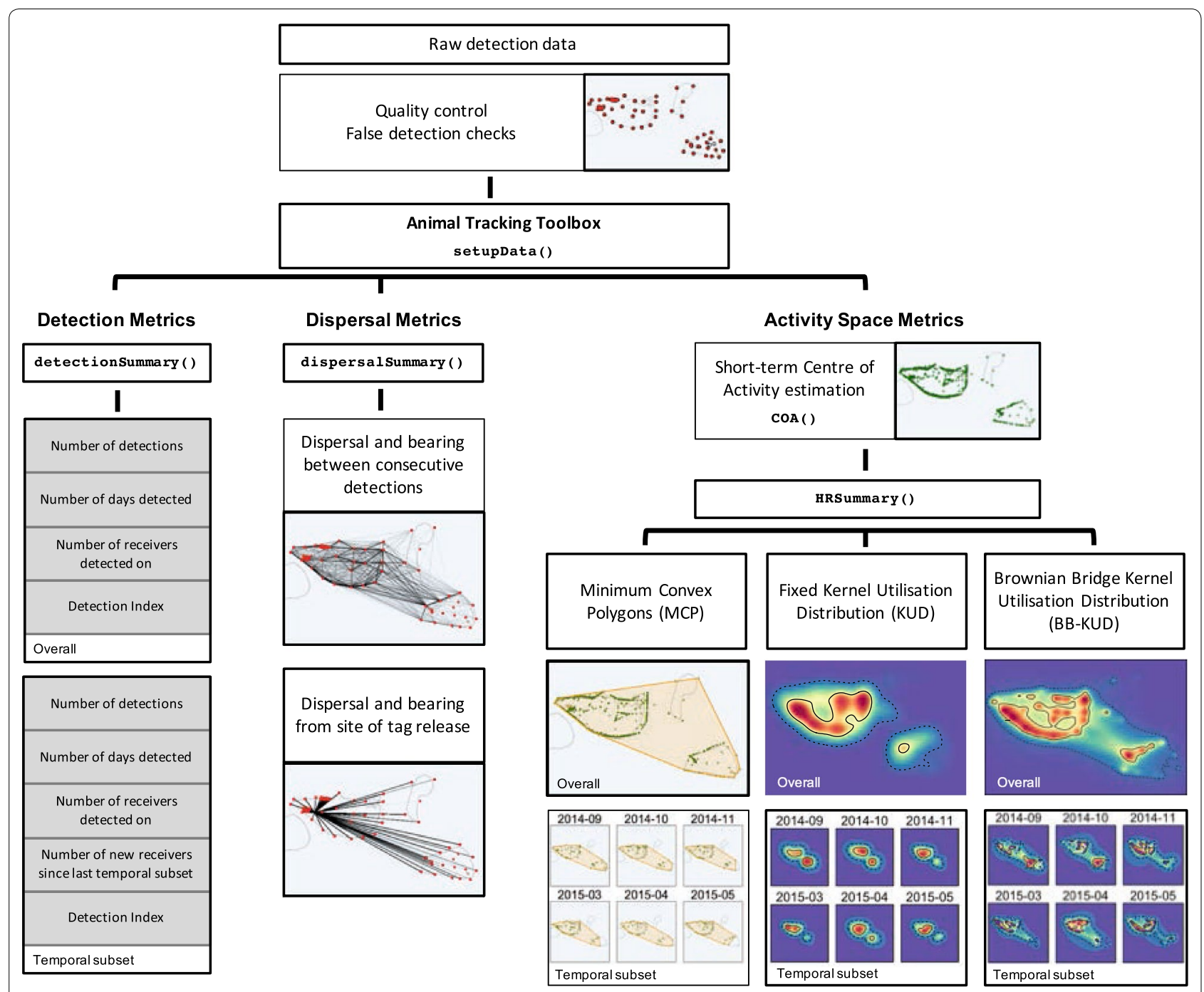

Fig. 1 Schematic of the proposed standardisation framework and workflow for calculating detection, dispersal, and activity space metrics from passive acoustic telemetry network data using new functions from the Animal Tracking Toolbox (ATT) (Table 1). Proposed workflow in R, input data requirements, and specifications of output are provided in the Appendix. Example detection data displayed in the figure are from a Tiger Shark (Galeocervo cuvier) passively monitored around Heron and One Tree Islands using the IMOS Animal Tracking Facility.

restricted activity spaces (95\% BB-KUD; $26.8 \pm 9.4 \mathrm{~km}^{2}$ and $7.9 \pm 3.6 \mathrm{~km}^{2}$, respectively) (Fig. 2).

\section{Case Study 2: Activity space and dispersal metrics of multiple species within a single site}

Activity space metrics of individuals from the three cooccurring species (Yellowfin Bream $n=3$, Yellowtail Kingfish $n=3$, and Bull Shark $n=3$ ) in Sydney Harbour were used to compare activity space metrics within a single site. A restricted number of individuals (three per species) were used to provide an illustrative example. Sample sizes are likely to be substantially larger in studies undertaking formal quantitative comparisons. The BB-KUD estimates showed that Bull Sharks displayed the largest activity spaces (95\% BB-KUD; $1204.3 \pm 158.1 \mathrm{~km}^{2}$; Fig. 3) and extended outside the Harbour area, followed by Yellowtail Kingfish $\left(40.7 \pm 29.4 \mathrm{~km}^{2}\right.$; Table 3$)$. In contrast, Yellowfin Bream displayed restricted activity spaces $\left(6.88 \pm 2.9 \mathrm{~km}^{2}\right)$ within only one tributary of the system (Fig. 3).

\section{Case Study 3: Examining temporal patterns in activity space across multiple species}

Patterns in asymptotic regression curves of cumulative minimum convex polygon (MCP) areas were most similar between the two shark species (Fig. 4). The majority of tagged Yellowtail 


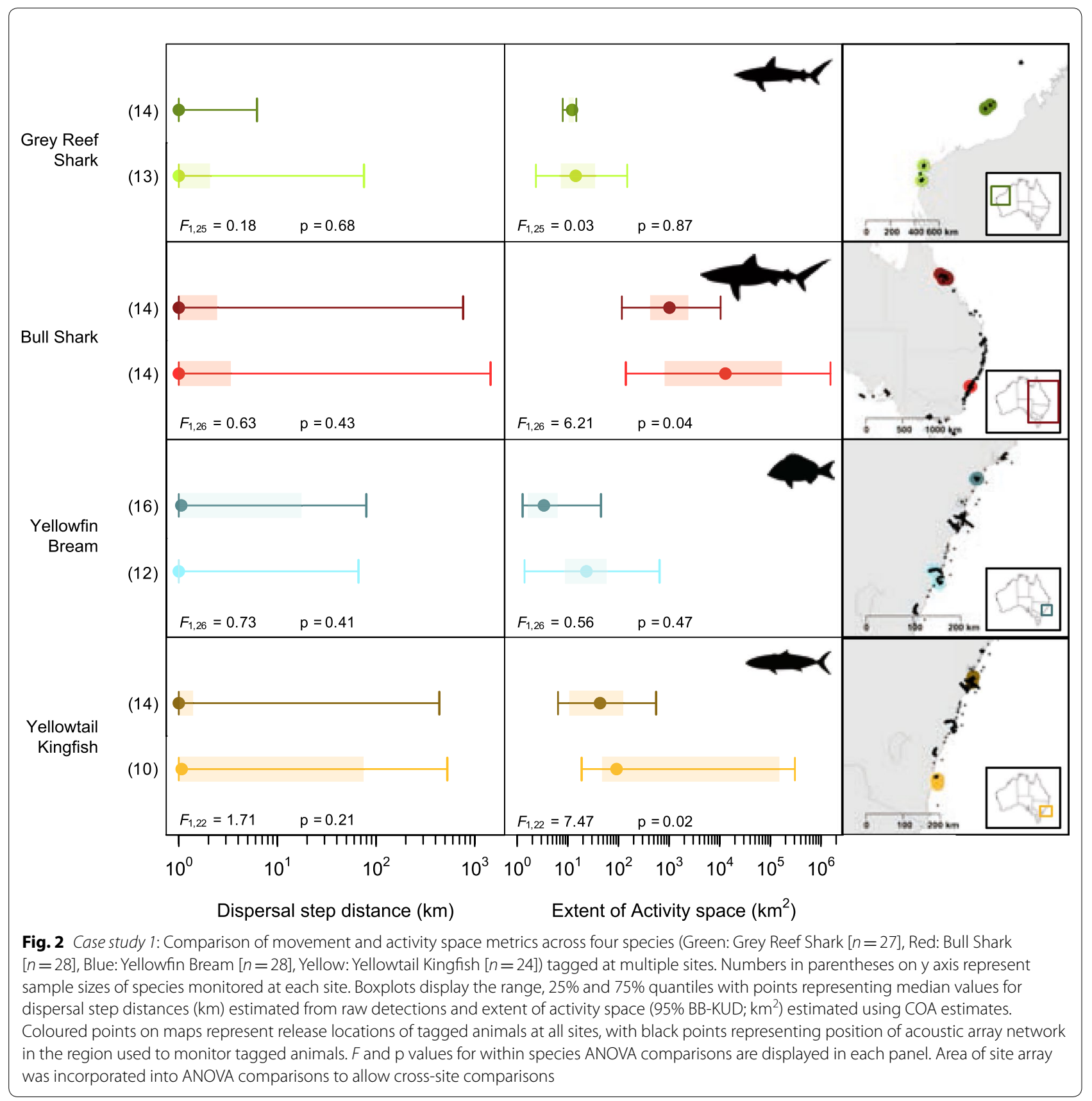

Kingfish displayed a stable MCP area relatively quickly (regression growth rate $=1.26 \pm 0.29$; doubling time $=0.55 \pm 0.19$ months) compared to the shark species (Bull Sharks: regression growth rate $=0.16 \pm 0.12$; doubling time $=4.28 \pm 0.81$ months; Grey Reef Shark: regression growth rate $=0.08 \pm 0.13$; doubling time $=7.89 \pm 1.08$ months; Fig. 4). In contrast, Yellowfin Bream reached a stable MCP area much later (regression growth rate $=0.07 \pm 0.43$; doubling time $=10.02 \pm 5.26$ months).

\section{Discussion}

We show that the ATT produces robust comparisons for not only single-species, regional-scale datasets but also among multiple species and locations in continentalscale datasets through standardisation in parameterisation and calculation of animal movement metrics. The 
Table 2 Case Study 1: Summary movement and activity space metrics calculated for four species at multiple sites within Australia

\begin{tabular}{|c|c|c|c|c|c|c|c|}
\hline \multirow[t]{2}{*}{ Species } & \multirow{2}{*}{$\begin{array}{l}\text { Number } \\
\text { of animals } \\
\text { tagged (n) }\end{array}$} & \multirow{2}{*}{$\begin{array}{l}\text { Site } \\
\text { of animal } \\
\text { release }\end{array}$} & \multirow{2}{*}{$\begin{array}{l}\text { Area of site } \\
\text { array }\left(\mathrm{km}^{2}\right)\end{array}$} & \multicolumn{2}{|c|}{ Step dispersal metrics (km) } & \multicolumn{2}{|c|}{ Brownian bridge KUD $\left(\mathrm{km}^{2}\right)$} \\
\hline & & & & $\begin{array}{l}\text { Mean step } \\
\text { dispersal } \\
\text { distance }\end{array}$ & $\begin{array}{l}\text { Maximum } \\
\text { step dispersal } \\
\text { distance }\end{array}$ & $\begin{array}{l}\text { Mean core activity } \\
\text { space ( } 50 \% \text { contour) }\end{array}$ & $\begin{array}{l}\text { Mean extent } \\
\text { of activity space } \\
\text { ( } 95 \% \text { contour) }\end{array}$ \\
\hline \multirow{2}{*}{$\begin{array}{l}\text { Grey Reef Shark } \\
\text { (Carcharhinus } \\
\text { amblyrhynchos) }\end{array}$} & 14 & North & 51.67 & $0.16 \pm 0.04$ & $2.09 \pm 0.36$ & $0.79 \pm 0.36$ & $10.65 \pm 1.99$ \\
\hline & 13 & South & 326.91 & $0.72 \pm 0.55$ & $21.65 \pm 7.42$ & $1.48 \pm 0.48$ & $30.31 \pm 11.36$ \\
\hline \multirow{2}{*}{$\begin{array}{l}\text { Bull Shark (Car- } \\
\text { charhinus leucas) }\end{array}$} & 14 & North & 917.62 & $3.66 \pm 1.62$ & $405.67 \pm 260.11$ & $1857.19 \pm 274.32$ & $9049.31 \pm 1888.96$ \\
\hline & 14 & South & 3839.43 & $4.43 \pm 1.74$ & $735.34 \pm 134.89$ & $49,289.13 \pm 38,812.96$ & $263,531.2 \pm 180,512.6$ \\
\hline \multirow{2}{*}{$\begin{array}{l}\text { Yellowfin Bream } \\
\text { (Acanthopagrus } \\
\text { australis) }\end{array}$} & 16 & North & 1121.15 & $7.28 \pm 4.76$ & $84.35 \pm 25.42$ & $0.87 \pm 0.42$ & $8.09 \pm 4.59$ \\
\hline & 12 & South & 951.12 & $0.28 \pm 0.13$ & $41.75 \pm 19.36$ & $7.63 \pm 6.53$ & $30.98 \pm 29.50$ \\
\hline \multirow{2}{*}{$\begin{array}{l}\text { Yellowtail Kingfish } \\
\text { (Seriola lalandi) }\end{array}$} & 14 & North & 2111.19 & $2.06 \pm 1.51$ & $82.76 \pm 29.66$ & $5.01 \pm 2.27$ & $126.28 \pm 50.02$ \\
\hline & 10 & South & 2267.13 & $11.99 \pm 10.48$ & $200.47 \pm 76.28$ & $14,988.99 \pm 14,988.85$ & $104,264.4 \pm 104,262.6$ \\
\hline
\end{tabular}

Northern and southern release sites for each species are represented in Fig. 2. Mean \pm SD of step dispersal metrics and KUD estimates across individuals tagged at each release site. The area of site arrays was estimated by calculating the area encompassing the listening ranges of all receivers within each regional installation. Area of site array was incorporated within each ANOVA comparison presented in Fig. 2

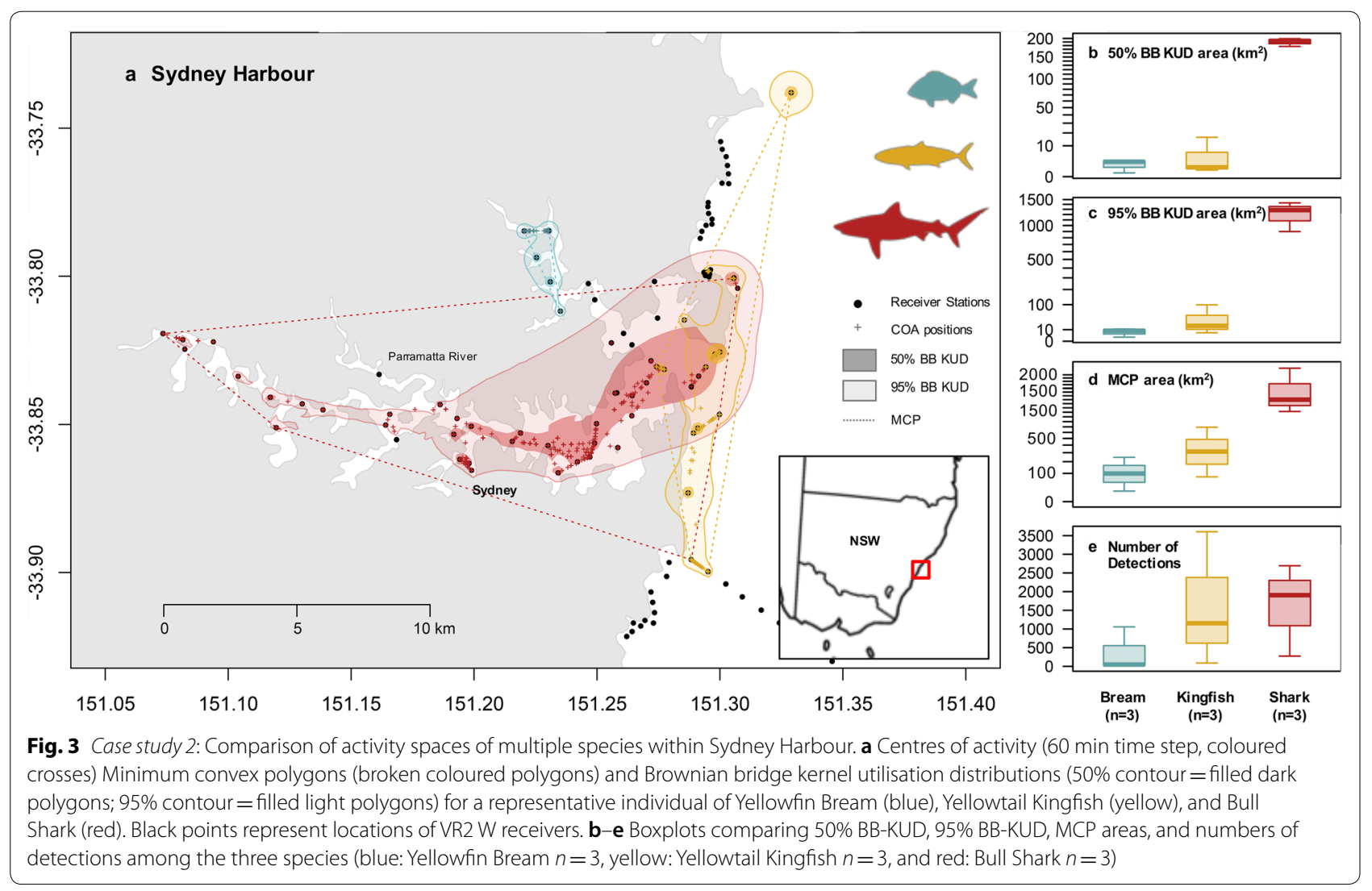

ability to calculate repeatable, standardised metrics permits exploration of variability at large geographic scales, at a population level, and potentially across a species' entire range. Further, the case studies highlight how the ATT can differentiate movement metrics within and between species, locations, and studies. Use of utilisation distributions based on Brownian Bridge movement models (BB-KUD) incorporate movement paths into activity space metrics and has been shown to more accurately represent activity spaces in mobile animals [29]. In 
Table 3 Case study 2: Summary detection and activity space metrics measured in tagged individuals within Sydney Harbour

\begin{tabular}{|c|c|c|c|c|}
\hline \multirow[t]{2}{*}{ Species } & \multirow{2}{*}{$\begin{array}{l}\text { Number of detections } \\
\text { within Sydney Harbour }\end{array}$} & \multirow{2}{*}{$\begin{array}{l}\text { Minimum Convex } \\
\text { Polygon area }\left(\mathrm{km}^{2}\right)\end{array}$} & \multicolumn{2}{|l|}{ Brownian bridge KUD area } \\
\hline & & & $50 \%$ BB-KUD area $\left(\mathrm{km}^{2}\right)$ & $95 \%$ BB-KUD area $\left(\mathrm{km}^{2}\right)$ \\
\hline Yellowfin Bream $(n=3)$ & $372.67 \pm 342.82$ & $11.96 \pm 6.77$ & $1.73 \pm 0.79$ & $6.88 \pm 2.94$ \\
\hline Yellowtail Kingfish $(n=3)$ & $1615.33 \pm 1041.26$ & $36.11 \pm 17.92$ & $5.87 \pm 5.19$ & $40.72 \pm 29.39$ \\
\hline Bull Shark $(n=3)$ & $1624.00 \pm 712.68$ & $151.01 \pm 36.13$ & $189.99 \pm 6.45$ & $1204.30 \pm 158.12$ \\
\hline
\end{tabular}

Mean \pm SD of detection and activity space metrics across each species tagged at Sydney Harbour

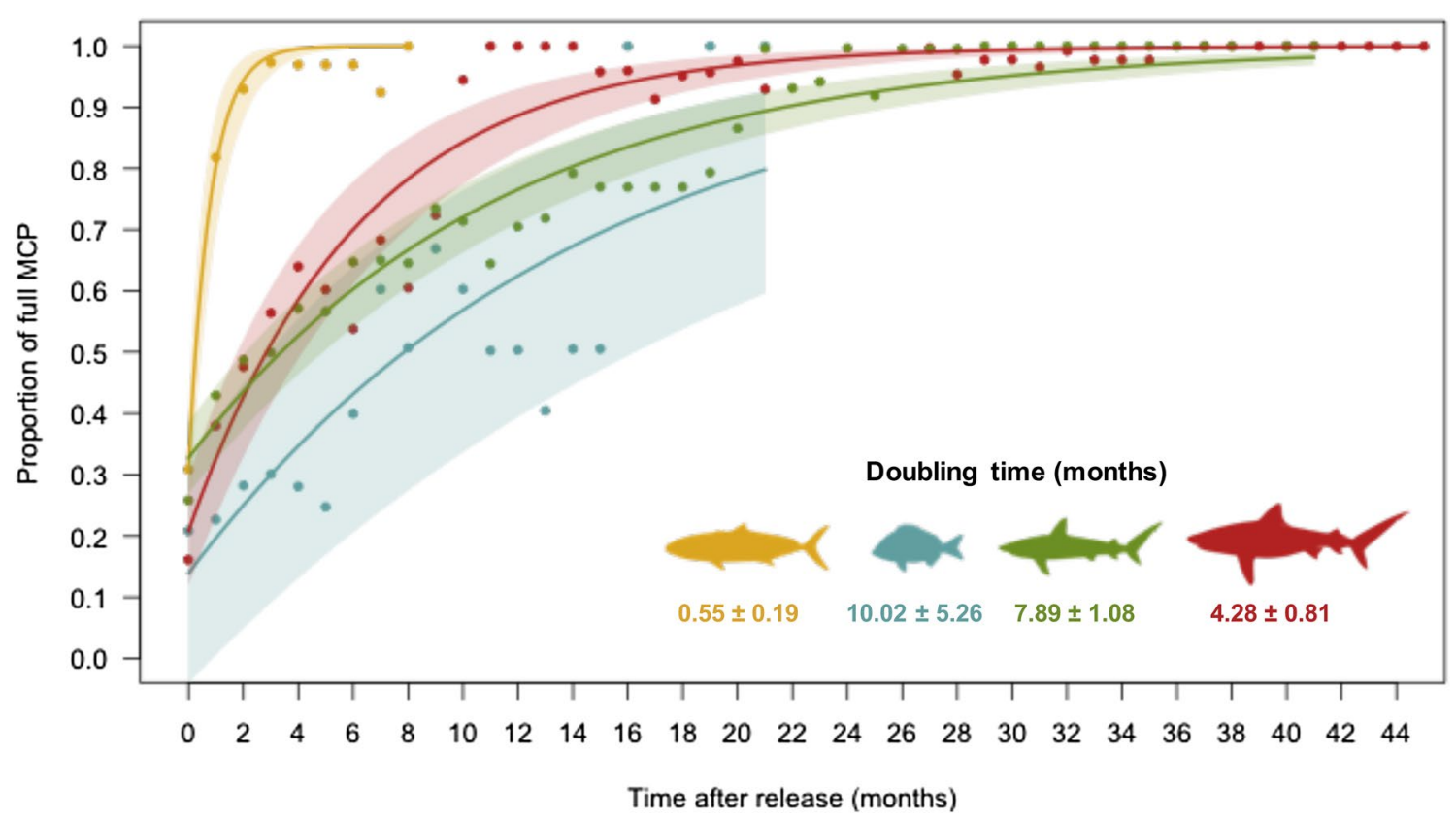

Fig. 4 Case study 3: Temporal patterns in activity space in multiple species. Asymptotic regression models of cumulative minimum convex polygon (MCP) in four species (yellow: Yellowtail Kingfish [ $n=24]$; blue: Yellowfin Bream [ $n=28]$; green: Grey Reef Shark [ $n=27]$; red: Bull Shark [ $n=28]$ ). Points represent mean values of cumulative MCP for each species each month after release. Lines represent fitted asymptotic regression model with shaded area representing $95 \%$ confidence intervals. Doubling times of species-specific regression models presented in months

the context of large-scale passive telemetry networks like the IMOS ATF, the use of BB-KUD to estimate activity space metrics incorporates movements between regional installations. The tool-set demonstrated here formalises the use of short-term centres of activity (COA) with kernel estimation techniques. The use of COA prior to kernel probability distribution calculation accounts for i) varied transmission settings often utilised by multiple researchers within a cooperative network, ii) spatial biases inherent to telemetry datasets obtained from fixed receiver stations, and iii) incorporate movements of tagged animals between fixed receivers in activity space metric calculations.

The utility of the proposed framework and ATT, exemplified by the case studies, is the ability to reliably compare dispersal and activity space metrics among multiple species representing different functional movement classes [15], tracked at a single location. As the parameters used in calculation of the metrics (i.e. smoothing parameters, COA time steps) were identical in the Sydney Harbour example, direct comparison of species was possible. Bull Sharks, which are known to be detected across distant receivers [15], had the largest activity centres and dispersal distances, but the highest activity centre remained within the estuary. This is consistent with previous findings that Bull Sharks can spend large amounts of time in a restricted area between large-scale movements [e.g. 30]. Yellowtail Kingfish and Yellowfin Bream had core activity centres approximately $9.8 \%$ and $1.5 \%$ (respectively) of those for Bull Sharks with Yellowfin 
Bream displaying minimal dispersal. This is consistent with a meta-analysis that identified these species as site-attached with occasional dispersal [15]. While some variability of movement patterns is expected within a functional movement class, the approach applied here allows a direct test of these classifications based on uniform and comparable metrics. Variability in individual movements patterns can result in individuals of a species belonging to more than one functional movement class [15], and a standardised approach to estimating metrics improves our ability to detect and define this variability.

\section{Applications of the ATT framework}

The ATT framework demonstrated above provides opportunities to address important questions at spatiotemporal scales not previously possible. Such questions include latitudinal comparisons and assessments of responses to global change, as well as exploration of fundamental ecological and evolutionary questions [31]. For example, Yellowfin Bream (Acanthopagrus australis) occur from $19^{\circ} \mathrm{S}$ to $38^{\circ} \mathrm{S}$ spanning over 19 degrees of latitude along Australia's east coast [32]. Passive animal tracking infrastructure spans most of this range, offering significant potential for comparative studies, but receiver arrays are managed across three state jurisdictions (i.e. Queensland, New South Wales, and Victoria). Several passive telemetry studies have been published on this species from investigations at four locations using a range of different metrics [e.g. 33-35]. While we do not dispute that each of these studies was valid within its individual scope, an opportunity was lost because direct behavioural comparisons and detection of changes in behaviour over time at a single location are impossible without full reanalysis. Robust comparisons would be greatly facilitated by employing the approach we have demonstrated here and may be particularly important since shifting environmental conditions in the ocean is of critical importance to understanding species' ability to adapt over spatial and temporal scales [36].

Comparative approaches have long been used to develop and test ecological and evolutionary questions [37], such as using morphometrics [38], stable isotope composition [39], or trophic level [40] to make inferences about differing ecological niches or behaviour in different environments. Comparative approaches based on passive telemetry are becoming increasingly common for interspecies comparisons, but are usually conducted as part of a single study $[41,42]$, or to contrast habitat use within species at different locations [43]. The benefits of standardising the approaches used to quantify behavioural parameters such as home range size have been noted in comparative studies [44]. This potential has yet to be realised, but is exemplified by case study 2 , where direct comparison among species within a single array revealed both inter-species overlap and differential habitat use patterns.

\section{Limitations and assumptions}

The metrics presented here have a solid foundation in spatial ecology [e.g. 45] and have previously been applied to a large number of species [e.g. 5, 46]. The benefit of the ATT is that this tool-set combines a large number of standard analyses used in acoustic telemetry into a single $\mathrm{R}$ package, accepts standard file formats, can be easily applied to a wide range of telemetry datasets in a repeatable fashion, and may be applied to a large number of individuals simultaneously (see Appendix). However, we caution that each metric has its own set of limitations, and these in turn require that some caveats be placed on the outputs derived.

The COA method [47] is currently included in the ATT (i.e. 'COA' function) and provides a means to temporally standardise detection data within the listening range of the receiver array. The process of estimating COA positions, however, assumes a homogeneous detection probability between all signal receiver stations (i.e. hydrophones, radio towers, PIT tag antennas). In reality, environmental and temporal factors along with transmitter specifications often influence detection probability $[41,48,49]$. Therefore, when analysing detection data from large-scale networks using the ATT, spatiotemporal variations in receiver detection probability need to be carefully considered and addressed using other methodological techniques (i.e. selecting appropriate radio-transmitter power outputs, range testing, sentinel tags).

Although the ATT allows for calculation of standardised dispersal and activity space metrics, the design of regional telemetry installations (e.g. curtains, grids) can heavily influence the output. Therefore, caution must be taken when directly comparing metrics from sites that have considerably different array designs. As in case study 1, properties of regional installations (e.g. area of array; number and spacing of receivers, grid vs. linear) should be incorporated into site comparisons, either through model weights (as undertaken in the present study) or through the calculation of weighted indices. Similarly, daily detection frequency and period of tag operation are used to calculate a 'Detection Index' over the full period of tagging as well as over temporal subsets. This index is calculated similarly to previously published metrics of residency [often referred to as Residency Index; e.g. 50]. However, the Detection Index provides a metric to assess the 'detectability' of an individual within the large-scale receiver network, and not a measure of residence within any particular location. Therefore, this index must be used and interpreted cautiously 
when conducting multi-site and landscape-level comparative spatial analyses.

\section{Conclusions}

Development of a tool-set for analysing data from a largescale network moves the field of spatial ecology beyond single-species or single-location approaches to facilitate national- and international-scale outputs that better reflect true animal distribution and connectivity. The main motivation for the development of the new functions within the ATT (Table 1, Fig. 1) was to facilitate the application of the proposed standardised framework and across largescale networks, principally for analyses among species and localities. When adopting the proposed framework and the ATT, it remains important to carefully consider the research questions being addressed, and whether a customised approach (e.g. tailored to the study site and array design) may be required. Although the case studies presented here demonstrate the capacity to extract standardised detection metrics, dispersal metrics, and activity space metrics from detection data acquired using passive acoustic telemetry (i.e. IMOS ATF database), this framework and tool-set can be applied to analyse other node-based passive telemetry datasets (e.g. from radio telemetry or radio-frequency identification; RFID) across a broad range of systems including marine [e.g. Ocean Tracking Network; 7], freshwater [e.g. GLATOS; http://glatos.glos.us], or terrestrial environments [e.g. Motus; 4]. The data acquired from these networks are similar to those exemplified here and consist of node-based detections which can be analysed through the proposed standardised framework and ATT to estimate metrics of activity space from tagged animals. The long-term benefit of adopting this tool-set and approach will likely arise from the capacity to compare results among arrays and support meta-analyses across substantial spatial scales to effectively address key questions in the field of animal movement ecology [2,31]. Additionally, we hope the adoption of the ATT will lead to increased collaboration between research and governmental agencies that currently utilise these technologies. The use of a standardised framework and calculation of comparable metrics across research groups, states, or countries will aid in designing appropriate cross-jurisdictional management and conservation policy for animals that migrate large distances. The proof of this concept will be the relative scale of its adoption by the research community.

\section{Methods}

\section{A universal approach for standardised metrics of activity space and movement}

Our framework follows a simple workflow within the R environment that allows for efficient calculation of detection, dispersal, and activity space metrics from uniquely identified tagged animals for the full life of tags and within user-defined temporal subsets. By standardising our workflow, we ensure that our calculation of metrics is consistent regardless of whether they were collected from a singular array, or across multiple projects within a large-scale tracking network. An example $\mathrm{R}$ workflow with $\mathrm{R}$ script is provided in the Appendix to highlight the new functionality of the ATT that allows estimation of detection, dispersal, and activity space metrics from passive telemetry data. The proposed workflow is briefly summarised here:

\section{Setting up data}

We acknowledge that multiple data structures are utilised by different passive telemetry technology providers (e.g. VEMCO, Lotek, BioMark) and by different cooperative networks (e.g. IMOS ATF, Motus, OTN). To enable an efficient workflow, the 'setupData' function within the ATT is used to standardise input data for subsequent functions (Table 1, Fig. 1). The function outputs an 'ATT' object that consists of a list of three key data sets associated with any passive telemetry data; a) detection data (e.g. detection timestamp, coordinates of detection), b) metadata information for each tag (e.g. tag life, species, biometrics of animal tagged), and c) receiver station information (e.g. locations of fixed receivers).

\section{(2)}

\section{Detection metrics}

The new ATT functions within the VTrack package enables the quick calculation of a number of commonly reported detection metrics including number of detections from a given tag, number of days detected, number of receivers the tag was detected on, and a Detection Index (commonly referred to as residency index) through the new 'detectionSummary' function (Fig. 1, Table 1). The Detection Index is simply the number of days a tag was detected on the array of receivers divided by the total number of days the tag was active. For this, additional information on tag life is required. The 'detectionSummary' function produces a list object with standardised detection metrics for the full tag life, as well as within specified temporal bins (e.g. monthly, weekly detection metrics).

\section{(3) Dispersal metrics}

Dispersal metrics commonly calculated using nodebased telemetry can provide information on dispersal potential of tagged animals with estimates of maximum dispersal capacities and velocities. Although such metrics estimated from fixed receiver arrays are dependent 
on array design and may be coarser in resolution than other technologies (e.g. satellite and GPS telemetry), they provide critical information on species too small to carry satellite tags and for longer periods. The ATT allows for quick estimation of two types of movement metrics; dispersal distances (in metres) and bearing (in degrees) between consecutive detections and between each detection, and tag release location, using the 'dispersalSummary' function (Fig. 1, Table 1). 'dispersalSummary' leverages the $s p$ functions 'spDistN1' to calculate distances and 'gzAzimuth' to calculate bearings between detection locations. These metrics can then be used to conduct further in-depth analyses. However, as mentioned previously care must be taken when analysing and interpreting dispersal distances and bearings from static receiver arrays, with biases related to array design considered in further analyses.

\section{Activity space metrics}

The coordination of large-scale passive telemetry networks can extend the listening range of smaller regional installations and enhance estimates of how much space far roaming animals occupy within a landscape or seascape. Detection data from a fixed array of receivers are inherently spatially biased depending on array design. The ATT workflow enables the estimation of activity space areas by accounting for the inherent spatial and temporal biases in telemetry data collected using a fixed array of receivers, by first estimating COA within user defined temporal bins [see 47] (Fig. 1). Additionally, the use of COAs account for differences in signal transmission delays that may be used by multiple researchers across a large-scale cooperative network. The toolbox uses the 'COA' function to estimate COA positions within user defined temporal bins (Table 1).

The ATT uses COA estimates from detection data to estimate activity space metrics using three commonly used techniques; a polygon-based technique: minimum convex polygons (henceforth $\mathrm{MCP}, \mathrm{m}^{2}$ ), and two kernelbased probability distribution techniques: fixed kernel utilisation distribution (henceforth KUD; $\mathrm{m}^{2}$ ) and utilisation distributions using a Brownian Bridge movement model (henceforth BB-KUD; $\mathrm{m}^{2}$ ). The functionality of the adehabitatHR package is used within the 'HRSummary' function to estimate the MCPs ('mcp' function), fixed KUDs ('kernelUD' function), and BB-KUDs ('kernelbb' function) [see [27] for details]. Core activity spaces (i.e. core home range) are estimated by calculating the area within the $50 \%$ contour of KUDs; similarly, the extent of activity spaces is estimated by calculating the area within the $95 \%$ contour for kernel-based activity space metrics (i.e. using the 'kernel.area' function in
adehabitatHR). Area of $100 \%$ MCPs, core, and extent of KUDs are calculated over the full tag life and within user-defined temporal subsets (i.e. monthly, weekly). In node-based studies, it is important to incorporate detections from every node the animals were detected at; thus, the $100 \%$ MCPs is utilised as a default; however, other thresholds can be applied. In addition, the 'HRSummary' function can also be set up to calculate cumulative activity space areas (e.g. cumulative MCPs, KUDs or BB-KUDs) for each temporal subset across the full tag life. Cumulative activity spaces for each temporal bin (i.e. each month or week) are calculated by adding COA locations from the next temporal bin to all previous COA locations for each tag. Trends in cumulative activity space metrics across the tag life can provide information on how tagged animals explore new areas within the receiver array and can identify periods of increased movement patterns [45].

The ATT functions highlighted above accommodate user-defined parameters to specify temporal sub-setting, time step binning for centre of activity calculations [see 47], types [i.e. MCP, fixed KUD, Brownian Bridge KUD], and parameters for activity space metric calculations [i.e. smoothing factor, extent, and grid size; see 27]; however, default values are provided to enable standardisation and ultimately comparison across multiple species and sites (see Appendix for details). The selection of smoothing parameters can greatly influence estimates of activity space when using utilisation distribution methods (Fig. 5) and ultimately effect capacity for direct comparison of outputs. Therefore, when reporting results from calculated metrics using the ATT, any user-defined parameters need to be highlighted to enable complete interpretation of estimated metrics.

\section{Spatiotemporal autocorrelation using passive telemetry data}

One key process within the proposed approach and workflow is the estimation of COA using the 'COA' function prior to calculation of activity spaces (i.e. for MCP, KUD, and BB-KUD area estimations; Fig. 1). This process attempts to account for the inherent biases in detection data from a fixed receiver array and across multiple tag transmission settings, by estimating positions of tagged animals within fixed time steps weighted by detections within the entire array [47]. The use of COA in consequent activity space metric calculations also accounts for biases in detections within the listening range of the network of arrays, where estimated activity spaces incorporate large dispersals across multiple arrays within the cooperative network. 


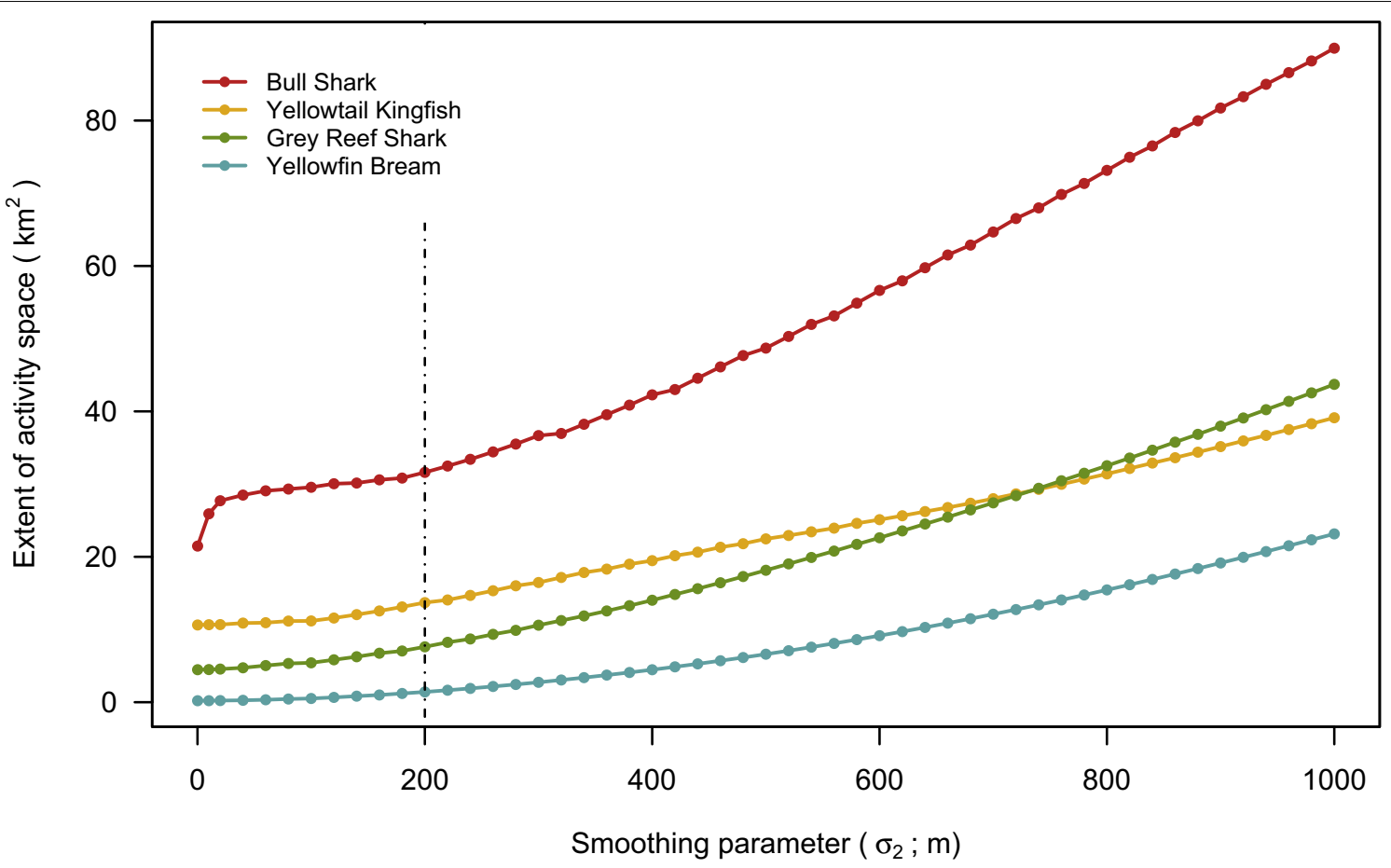

Fig. 5 The influence of smoothing parameter selection $\left(\delta_{2}\right)$ in the resulting extent of activity space estimates for a single individual from four species tracked using the IMOS ATF acoustic telemetry network. Activity space estimates were calculated using utilisation distributions from Brownian Bridge movement models (95\% BB-KUD) with $\delta_{1}$ parameter selected using a maximum likelihood technique (see methods). Default value of $\delta_{2}$ used in ATT $(200 \mathrm{~m})$ is denoted by the vertical broken line and has been chosen as a conservative estimate of listening range of acoustic receivers used in the IMOS ATF network

\section{Parameterising activity space metrics}

The approach includes activity space estimation using commonly used techniques including MCPs and fixed KUD as well as techniques that incorporate movement paths by utilising the Brownian Bridge movement model [BB-KUD; 29] (Fig. 1). Smoothing factors significantly influence calculated estimates of activity space metrics using kernel methods [Fig. 5; 23, 27]. The fixed KUD method requires a single smoothing parameter $\left(\delta_{2}\right)$ related to imprecision of relocation. Application of a single, common smoothing parameter results in a standardised output that can be directly compared across species and locations. For passive acoustic telemetry datasets, the $\delta_{2}$ parameter is related to the hydrophone detection range. The ATT uses a default value of $200 \mathrm{~m}$ which is a conservative estimate of the listening range for omnidirectional hydrophones used in most passive acoustic telemetry arrays [Fig. 5; 48, 49]. Smoothing parameters greater than $200 \mathrm{~m}$ in acoustic telemetry studies result in a correlative increase in the estimated spatial extent of activity space, suggesting over estimation (Fig. 5). Nevertheless, this smoothing parameter can also be user-defined if a more precise value of detection range is known, and to accommodate analysis of data from other telemetry technologies such as radio towers [detection range of $\sim 1-20 \mathrm{~km}$ based on radio transmitters; 4] (see Appendix).

The BB-KUD method requires the selection of two smoothing factors related to speed of the animal and imprecision of relocations, $\delta_{1}$ and $\delta_{2}$, respectively. Parameterisation of the BB-KUD within the proposed approach can be undertaken by estimating the $\delta_{1}$ smoothing parameter using a maximum likelihood estimation process based on a selected $\delta_{2}$ value [see 27]. The selection of smoothing factor when estimating activity space should be made considering passive tracking technology used (i.e. radio towers, acoustic telemetry) and information on the listening range of signal receivers used.

\section{Case studies}

Three case studies are presented for comparative spatial analyses of dispersal and activity spaces across four species and multiple locations. Case studies include: (1) analysis of multiple species across multiple study sites; (2) analysis of multiple species within a single site; and (3) temporal patterns in activity space in multiple species across multiple sites. Data for case studies were sourced from the IMOS ATF database, a publicly accessible 
online repository that stores raw detection data collected by researchers conducting animal movement studies in Australia. These data undergo strict quality control checks [12] and can be accessed through the Australian Ocean Data Network portal (AODN: https://portal.aodn. org.au/). Metadata provide detailed information on tag type, sensors, release location, and biological attributes (e.g. species, sex, body length) of tagged animals.

\section{Species selection and description}

A subset of quality-controlled detection data from four species (Yellowfin Bream, Acanthopagrus australis $n=28$ tags; Yellowtail Kingfish, Seriola lalandi $n=24$ tags; Grey Reef Shark, Carcharhinus amblyrhynchos $n=27$ tags; and Bull Shark, Carcharhinus leucas $n=28$ tags) were used. These species have been tagged by multiple researchers for multiple projects at multiple locations around Australia and are representatives of different functional movement classes [FMCs; 15]. Here, we illustrate the utility of the ATT for examining activity space across different FMCs.

Yellowfin Bream (Acanthopagrus australis) are a temperate marine estuarine-opportunist fish distributed across eastern Australia, classified primarily in the 'occasional' FMC as individuals are site-attached with occasional medium level dispersals $(\sim 2 \mathrm{~km})$ [15]. Yellowtail Kingfish (Seriola lalandi) are a wide-ranging coastal pelagic predatory species distributed throughout the sub-tropical and temperate waters of the southern hemisphere and have been tracked at multiple locations with movement patterns classifying them within the 'occasional' FMC [15]. Grey Reef Sharks (Carcharhinus amblyrhynchos) have been monitored at multiple reef habitats around Australia (e.g. fringing reef systems, reef atolls), with detection and movement data classify them within the 'resident' FMC, where individuals were highly site-attached with very low levels of dispersal between adjacent reef systems [15]. Bull Sharks (Carcharhinus leucas) have been monitored at multiple locations with data revealing individuals undertaking nomadic, long distance migrations between tropical and temperate regions [30], classifying them within the 'roamer' FMC [15].

\section{Species comparisons}

In case study 1 , dispersal and activity space metrics were compared between four species monitored on the IMOS ATT network at multiple locations around Australia. The standardisation framework and ATT were used to calculate metrics of dispersal between consecutive raw detections (range, median, $25 \%$ and $75 \%$ quantiles of step distances) and activity space using COA estimates (50\% and 95\% BB-KUD) for the four selected species that were monitored at multiple sites around Australia (Fig. 2).
Metrics calculated using a common smoothing parameter were compared within and between species, and sites using linear regression models weighted by the area covered by site-specific acoustic arrays. Two-way ANOVAs were then conducted using weighted linear regression models to assess differences in dispersal and activity space metrics between sites and species. Weighted models were created using the ' $1 \mathrm{~m}$ ' function in the $\mathrm{R}$ stats package [25], with the area covered by site-specific arrays for each monitored individual included as a model weight (using the 'weights' parameter).

In case study 2, detection and activity space metrics were compared between three species (Yellowfin Bream $n=3$, Yellowtail Kingfish $n=3$, and Bull Sharks $n=3$ ) monitored by multiple research projects within a single study site. The ATT was used to summarise detection metrics and estimate activity spaces of three species monitored within Sydney Harbour (S 33.847 ${ }^{\circ}$, E $\left.151.189^{\circ}\right)$. The area covered by the regional installation at Sydney Harbour includes $\sim 418.7 \mathrm{~km}^{2}$ and covers the full extent of the Parramatta River and extends $\sim 20 \mathrm{~km}$ north and south along the coast from the mouth of the catchment (Fig. 3). Detection metrics, MCP area, and BB-KUD areas for three individuals of Yellowfin Bream, Yellowtail Kingfish, and Bull Sharks tagged and monitored within Sydney harbour were visually compared.

In case study 3, the ATT was used to examine differences in the rate species reach a stable activity space. MCPs were chosen to estimate a temporal threshold at which activity space stabilises instead of probability distribution methods (i.e. fixed KUD, BB-KUD) as measures of cumulative MCP are straightforward to interpret, and do not decay with increasing numbers of detections accumulated over time. Cumulative monthly MCP areas were calculated over the full monitoring period for all individuals from the four selected species (Yellowfin Bream $n=28$, Yellowtail Kingfish $n=24$, Grey Reef Shark $n=27$, and Bull Shark $n=28$ ). Increasing trends in cumulative activity space since tag release were assessed first by standardising monthly cumulative areas as a proportion of full MCP area (i.e. MCP area estimated using full detection dataset for each individual). Species-specific asymptotic regression models were fitted to monthly cumulative MCP areas to quantify and compare patterns in activity space between the four species. MCP area doubling times and regression growth rates were estimated using model coefficients and compared between species.

\section{Authors' contributions}

VU developed the R code for the Animal Tracking Toolbox, conducted the analyses, and led the writing of the manuscript. RGD and XH were major contributors in developing the ATT code, interpreting the analyses, and writing the manuscript. RCB, SB, HAC, CAS, MDT, CH, FRAJ contributed data and assisted in developing the analysis framework and writing the manuscript. 
$\mathrm{RGH}$ and MRH were major contributors in developing the analysis framework, contributing data, and writing the manuscript. All authors read and approved the final manuscript.

\section{Author details}

${ }^{1}$ Arafura Timor Research Facility, Australian Institute of Marine Science, Darwin, NT 0810, Australia. ${ }^{2}$ Centre for Sustainable Tropical Fisheries and Aquaculture \& College of Science and Engineering, James Cook University, Townsville, QLD 4811, Australia. ${ }^{3}$ The School of Biological Sciences, The University of Queensland, St. Lucia, QLD 3052, Australia. ${ }^{4}$ Australian Ocean Data Network, Integrated Marine Observing System, University of Tasmania, Private Bag 110, Hobart, TAS 7001, Australia. ${ }^{5}$ CSIRO, Oceans and Atmosphere, Queensland Biosciences Precinct, St. Lucia, QLD 4072, Australia. ${ }^{6}$ School of Biological, Earth and Environmental Sciences, University of New South Wales, Sydney, NSW 2052, Australia. ${ }^{7}$ Institute of Marine Science, University of California Santa Cruz, Santa Cruz, CA 95064, USA. ${ }^{8}$ Research Institute for the Environment and Livelihoods, Charles Darwin University, Darwin, NT 0909, Australia. ${ }^{9}$ Sydney Institute of Marine Science, Mosman, NSW 2088, Australia. ${ }^{10}$ Department of Biological Sciences, Macquarie University, North Ryde, NSW 2109, Australia. ${ }^{11}$ College of Science and Engineering, Flinders University, Bedford Park, Adelaide, SA 5042, Australia. ${ }^{12}$ Port Stephens Fisheries Institute, New South Wales Department of Primary Industries, Taylors Beach, NSW 2315, Australia. ${ }^{13}$ Australian Institute of Marine Science, Townsville, QLD 4810, Australia.

\section{Acknowledgements \\ Quality checked telemetry data used in case studies were sourced from the Australian Ocean Data Network portal (https://portal.aodn.org.au/) and the IMOS ATF (www.imos.org.au). IMOS is a national collaborative research infrastructure supported by the Australian Government. We thank the PIs of the Logan TERN, NSW DPI Jervis Bay, NSW DPI Artificial Reef Network, NSW DPI CEFT, NRETA, NSW DPI coastal sharks, and QLD Large Sharks projects for use of their data in case studies. We also acknowledge contributions of all collabora-} tors and their institutions to the content of the IMOS ATF database.

\section{Competing interests}

The authors declare that they have no competing interests.

\section{Availability of data and materials}

The datasets analysed during the current study are available in the Australian Ocean Data Network, https://portal.aodn.org.au. The VTrack package can be accessed from the CRAN repository (https://cran.r-project.org/web/packages/ VTrack/index.html) and via the R statistical environment. The development code for all functions and quick guide to using the code is available on the GitHub repository https://github.com/rossdwyer/NTrack.

\section{Consent for publication}

Not applicable.

Ethics approval and consent to participate

Not applicable.

\section{Funding}

Funding for the research was provided by the Integrated Marine Observing System.

\section{Appendix}

The VTrack package can be accessed from the CRAN repository (https://cran.r-project.org/web/packages/VTrac $\mathrm{k} / \mathrm{index} . \mathrm{html}$ ) and via the $\mathrm{R}$ statistical environment. The development code for all functions and quick guide to using the code is available on the GitHub repository https ://github.com/rossdwyer/VTrack. The GitHub page also houses a wiki page and vignette that highlights the data formats, requirements, and proposed workflow.

\section{Publisher's Note}

Springer Nature remains neutral with regard to jurisdictional claims in published maps and institutional affiliations.

Received: 18 May 2018 Accepted: 28 November 2018

Published online: 13 December 2018

\section{References}

1. Block BA, Jonsen ID, Jorgensen SJ, Winship AJ, Shaffer SA, Bograd SJ, et al. Tracking apex marine predator movements in a dynamic ocean. Nature. 2011;475(7354):86-90. https://doi.org/10.1038/nature10082.

2. Bridge ES, Thorup K, Bowlin MS, Chilson PB, Diehl RH, Fléron RW, et al. Technology on the move: recent and forthcoming innovations for tracking migratory birds. Bioscience. 2011;61(9):689-98. https://doi. org/10.1525/bio.2011.61.9.7.

3. Cooke SJ, Hinch SG, Wikelski M, Andrews RD, Kuchel L, Wolcott TG, et al. Biotelemetry: a mechanistic approach to ecology. Trends Ecol Evol. 2004;19(6):334-43.

4. Taylor PD, Crewe TL, Mackenzie SA, Lepage D, Aubry Y, Crysler Z, et al. The Motus Wildlife Tracking System: a collaborative research network to enhance the understanding of wildlife movement. Avian Conserv Ecol. 2017. https://doi.org/10.5751/ace-00953-120108.

5. Hussey NE, Kessel ST, Aarestrup K, Cooke SJ, Cowley PD, Fisk AT, et al. Aquatic animal telemetry: a panoramic window into the underwater world. Science. 2015;348(6240):1255642. https://doi.org/10.1126/scien ce.1255642.

6. Crossin GT, Heupel MR, Holbrook CM, Hussey NE, Lowerre-Barbieri SK, Nguyen VM, et al. Acoustic telemetry and fisheries management. Ecol Appl. 2017. https://doi.org/10.1002/eap.1533.

7. Cooke SJ, Iverson SJ, Stokesbury MJW, Hinch SG, Fisk AT, VanderZwaag DL, et al. Ocean Tracking Network Canada: a network approach to addressing critical issues in fisheries and resource management with implications for ocean governance. Fisheries. 2011;36(12):583-92. https:// doi.org/10.1080/03632415.2011.633464.

8. Moustahfid H, Grimes C, Kocik J, Block B, Holland K, Payne J, et al. Toward a national Animal Telemetry Observing Network (ATN) for our oceans, coasts and great lakes: workshop synthesis report (U.S. IOOS workshop, March 2011, Santa Cruz, California). NOAA-TM-NMFS-SWFSC-482: U.S. Department of Commerce, NOAA Technical Memorandum NMFS2011.

9. Cowley P, Bennett R, Childs A, Murray T. Reflection on the first five years of South Africa's Acoustic Tracking Array Platform (ATAP): status, challenges and opportunities. Afr J Mar Sci. 2017;39(4):363-72.

10. Mees J, Seys J, editors. Book of abstracts - VLIZ Marine Scientist Day. Flanders Marine Institute (VLIZ), Oostende: VLIZ Special Publication 75; 2016.

11. Hill K, Moltmann T, Proctor R, Allen S. The Australian Integrated Marine Observing System: delivering data streams to address national and international research priorities. Mar Technol Soc J. 2010;44(6):65-72.

12. Hoenner $X$, Huveneers $C$, Steckenreuter A, Simpfendorfer C, Tattersall K,

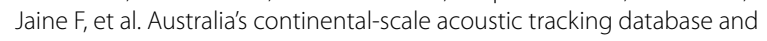
its automated quality control process. Sci Data. 2018;5:170206. https:// doi.org/10.1038/sdata.2017.206.

13. Nguyen VM, Brooks JL, Young N, Lennox RJ, Haddaway N, Whoriskey FG, et al. To share or not to share in the emerging era of big data: Perspectives from fish telemetry researchers on data sharing. Can J Fish Aquat Sci. 2017. https://doi.org/10.1139/cjfas-2016-0261.

14. Campbell HA, Beyer HL, Dennis TE, Dwyer RG, Forester JD, Fukuda Y, et al. Finding our way: on the sharing and reuse of animal telemetry data in Australasia. Sci Total Environ. 2015;534:79-84. https://doi.org/10.1016/j. scitotenv.2015.01.089.

15. Brodie S, Lédée EJI, Heupel MR, Babcock RC, Campbell HA, Gledhill DC, et al. Continental-scale animal tracking reveals functional movement classes across marine taxa. Sci Rep. 2018;8(1):3717. https://doi. org/10.1038/s41598-018-21988-5.

16. Kie JG, Matthiopoulos J, Fieberg J, Powell RA, Cagnacci F, Mitchell MS, et al. The home-range concept: are traditional estimators still relevant 
with modern telemetry technology? Philos Trans R Soc B Biol Sci. 2010;365(1550):2221-31. https://doi.org/10.1098/rstb.2010.0093.

17. Kie JG. A rule-based ad hoc method for selecting a bandwidth in kernel home-range analyses. Anim Biotelemetry. 2013;1 (13):1-12. https://doi. org/10.1186/2050-3385-1-13.

18. Fieberg J, Börger L. Could you please phrase "home range" as a question? J Mammal. 2012;93(4):890-902. https://doi. org/10.1644/11-MAMM-S-172.1.

19. Pillans RD, Babcock RC, Thomson DP, Haywood MDE, Downie RA, Vanderklift MA, et al. Habitat effects influences on home range and schooling behaviour in an herbivorous fish (Kyphosus bigibbus) revealed by acoustic tracking. Mar Freshw Res. 2017; 68(8):1454-67. https://doi.org/10.1071/ MF16199.

20. Pillans RD, Bearham D, Boomer A, Downie R, Patterson TA, Thomson DP, et al. Multi year observations reveal variability in residence of a tropical demersal fish, Lethrinus nebulosus: implications for spatial management. PLoS ONE. 2014;9(9):e105507. https://doi.org/10.1371/journal.pone.01055 07.

21. Speed CW, Meekan MG, Field IC, McMahon CR, Harcourt RG, Stevens $\mathrm{JD}$, et al. Reef shark movements relative to a coastal marine protected area. Reg Stud Mar Sci. 2016;3:58-66. https://doi.org/10.1016/j. rsma.2015.05.002.

22. Escalle L, Speed CW, Meekan MG, White WT, Babcock RC, Pillans RD, et al. Restricted movements and mangrove dependency of the nervous shark Carcharhinus cautus in nearshore coastal waters. J Fish Biol. 2015;87(2):323-41. https://doi.org/10.1111/jfb.12724.

23. Dwyer RG, Campbell HA, Irwin TR, Franklin CE. Does the telemetry technology matter? Comparing estimates of aquatic animal space-use generated from GPS-based and passive acoustic tracking. Mar Freshw Res. 2015;66(7):654-64.

24. Rogers KB, White GC. Analysis of movement and habitat use from telemetry data. In: Guy SC, Brown ML, editors. Analysis and interpretation of freshwater fisheries data. Bethesda: American Fisheries Society; 2007. p. 625-76.

25. R Development Core Team. R: A language and environment for statistical computing (version 3.3.2). Vienna: R Foundation for Statistical Computing; 2016.

26. Campbell HA, Watts ME, Dwyer RG, Franklin CE. V-Track: software for analysing and visualising animal movement from acoustic telemetry detections. Mar Freshw Res. 2012;63(9):815-20. https://doi.org/10.1071/ MF12194.

27. Calenge C. The package "adehabitat" for the R software: a tool for the analysis of space and habitat use by animals. Ecol Modell. 2006;197(34):516-9. https://doi.org/10.1016/j.ecolmodel.2006.03.017.

28. Bivand RS, Pebesma EJ, Gómez-Rubio V, Pebesma EJ. Applied spatial data analysis with R. Berlin: Springer; 2008.

29. Horne JS, Garton EO, Krone SM, Lewis JS. Analysing animal movements using brownian bridges. Ecology. 2007;88(9):2354-63. https://doi. org/10.1890/06-0957.1.

30. Heupel MR, Simpfendorfer CA, Espinoza M, Smoothey AF, Tobin AJ, Peddemors V. Conservation challenges of sharks with continental scale migrations. Front Mar Sci. 2015. https://doi.org/10.3389/fmars.2015.00012

31. Hays GC, Ferreira LC, Sequeira AMM, Meekan MG, Duarte CM, Bailey H, et al. Key questions in marine megafauna movement ecology. Trends Ecol Evol. 2016;31(6):463-75. https://doi.org/10.1016/j.tree.2016.02.015.

32. Pollock BR. Movements and migrations of yellowfin bream, Acanthopagrus australis (Gunther), in Moreton May, Queensland as determined by tag recoveries. J Fish Biol. 1982;20(3):245-52.

33. Gannon R, Payne NL, Suthers IM, Gray CA, van der Meulen DE, Taylor $M D$. Fine-scale movements, site fidelity and habitat use of an estuarine dependent sparid. Environ Biol Fishes. 2015;98:1599-608. https://doi. org/10.1007/s10641-015-0385-5.
34. Payne NL, van der Meulen DE, Gannon R, Semmens JM, Suthers IM, Gray $C A$, et al. Rain reverses diel activity rhythms in an estuarine teleost. Proc $R$ Soc B. 2013. https://doi.org/10.1098/rspb.2012.2363.

35. Taylor MD, van der Meulen DE, Brodie S, Cadiou G, Knott NA. Applying acoustic telemetry to understand contaminant exposure and bioaccumulation patterns in mobile fishes. Sci Total Environ. 2018;625:344-54.

36. García Molinos J, Halpern BS, Schoeman DS, Brown CJ, Kiessling W, Moore $\mathrm{PJ}$, et al. Climate velocity and the future global redistribution of marine biodiversity. Nat Clim Change. 2016;6(1):83-8. https://doi.org/10.1038/ nclimate2769.

37. Horn HS. Measurement of "Overlap" in comparative ecological studies. Am Nat. 1966;100(914):419-24. https://doi.org/10.1086/282436.

38. Bellwood DR, Wainwright PC, Fulton CJ, Hoey A. Assembly rules and functional groups at global biogeographical scales. Funct Ecol. 2002;16(5):557-62.

39. Newsome SD, Clementz MT, Koch PL. Using stable isotope biogeochemistry to study marine mammal ecology. Mar Mamm Sci. 2010;26(3):50972. https://doi.org/10.1111/j.1748-7692.2009.00354.x.

40. Pauly D, Christensen V, Walters C. Ecopath, Ecosim, and Ecospace as tools for evaluating ecosystem impact of fisheries. ICES J Mar Sci. 2000;57(3):697-706.

41. Kays R, Tilak S, Crofoot M, Fountain T, Obando D, Ortega A, et al. Tracking animal location and activity with an Automated Radio Telemetry System in a tropical rainforest. Comput J. 2011;54(12):1931-48. https://doi. org/10.1093/comjnl/bxr072.

42. Espinoza M, Lédée EJl, Simpfendorfer CA, Tobin AJ, Heupel MR. Contrasting movements and connectivity of reef-associated sharks using acoustic telemetry: implications for management. Ecol Appl. 2015;25(8):2101-18. https://doi.org/10.1890/14-2293.1

43. Parsons DM, Morrison MA, Slater MJ. Responses to marine reserves: decreased dispersion of the sparid Pagrus auratus (snapper). Biol Conserv. 2010;143(9):2039-48. https://doi.org/10.1016/j.biocon.2010.05.009.

44. Nash KL, Welsh JQ, Graham NAJ, Bellwood DR. Home-range allometry in coral reef fishes: comparison to other vertebrates, methodological issues and management implications. Oecologia. 2015;177(1):73-83. https://doi. org/10.1007/s00442-014-3152-y.

45. Heupel MR, Simpfendorfer CA, Hueter RE. Estimation of shark home ranges using passive monitoring techniques. Environ Biol Fishes. 2004;71(2):135-42.

46. Mclntyre T. Trends in tagging of marine mammals: a review of marine mammal biologging studies. Afr J Mar Sci. 2014;36(4):409-22. https://doi. org/10.2989/1814232X.2014.976655.

47. Simpfendorfer CA, Heupel MR, Hueter RE. Estimation of short-term centers of activity from an array of omnidirectional hydrophones and its use in studying animal movements. Can J Fish Aquat Sci. 2002;59(1):23-32. https://doi.org/10.1139/f01-191.

48. Kessel ST, Cooke SJ, Heupel MR, Hussey NE, Simpfendorfer CA, Vagle $\mathrm{S}$, et al. A review of detection range testing in aquatic passive acoustic telemetry studies. Rev Fish Biol Fish. 2013. https://doi.org/10.1007/s1116 0-013-9328-4.

49. Huveneers C, Simpfendorfer CA, Kim S, Semmens JM, Hobday AJ, Pederson $\mathrm{H}$, et al. The influence of environmental parameters on the performance and detection range of acoustic receivers. Methods Ecol Evol. 2016;7(7):825-35. https://doi.org/10.1111/2041-210X.12520.

50. Afonso P, Fontes J, Holland KN, Santos RS. Social status determines behaviour and habitat usage in a temperate parrotfish: implications for marine reserve design. Mar Ecol Prog Ser. 2008;359:215-27. 